\title{
La evolución sociohistórica semiótica del verbo como representante de la experiencia
}

Ana Luisa Forzán De Lachica

\section{Resumen}

El objetivo de esta revisión fue describir la evolución sociohistórica de la construcción del significado y signo del verbo en la lengua española como representante de la experiencia (lo dinámico) en oposición a la sustancia (lo estático). Lo anterior, con el fin de encontrar pistas para la reflexión del desarrollo cognitivo con énfasis en la formación del símbolo de la experiencia. Con base en los grandes debates de filósofos, lingüistas y gramáticos describimos el proceso sociohistórico desde la época clásica con los gramáticos grecolatinos hasta nuestros días. También realizamos una reconstrucción de hechos a través del empleo de evidencias documentales confiables. La exploración sociohistórica nos permitió dimensionar lo que los principales lingüistas y académicos de la lengua española han demostrado sobre la dificultad que presenta esta categoría por su riqueza formal, sintáctica y semántica. Si dicha riqueza y complejidad las llevamos al campo del desarrollo cognitivo, específicamente en la formación del símbolo en el niño, para advertir algunos indicios puede 
resultar interesante. Eventualmente, esta exploración puede colaborar para dialogar con los planteamientos que abordan dicha formación a partir de la sustancia e indagar sobre la formación del símbolo de la experiencia.

Palabras clave: Lengua española; representación experiencia; revisión sociohistórica; semiótica.

\section{Introducción}

El símbolo es una poderosa categoría de análisis en el contexto del desarrollo psicológico. Los signos de los distintos sistemas de representación separan de lo inmediato y cuentan con una triple función: social, cognitiva y comunicativa. La formación del símbolo en el niño ha sido un problema de investigación abordado abundantemente a lo largo de los años.

Las dos perspectivas principales que identificamos responden a una formación del símbolo como una reconstrucción individual y otra como resultado de la interacción social. La primera, afirma que la construcción del signo en el niño es resultado de la interacción directa del sujeto con el objeto (signo) y que es el niño quien reconstruye el objeto cultural de forma individual, activa e interna (Piaget, 1959 y 2012; Inhelder, Lezine, Sinclair y Stambak, 1972; McCune-Nicholich, 1981; entre otros). La segunda perspectiva debate con la primera ya que, en términos generales, considera que el símbolo responde a un origen social y por tanto está inscrito en las prácticas sociales relacionadas con otros aspectos del desarrollo como el lenguaje. En esta perspectiva agrupamos planteamientos diversos que explican la formación del símbolo en el niño como resultado de su interacción y, a la vez, con un otro como representante de la cultura (Vigotsky, 1930 y 1996; El'konin, 1966; Rodríguez y Moro, 2002; Palacios, 2009; Tomasello, 1999; entre otros).

En este estudio no ahondaremos en estos modelos explicativos ya que excede al objetivo del mismo. Lo presentamos a manera de introducción para sugerir que la comprensión de la evolución sociohistórica semiótica del verbo como representante de la experiencia eventualmente puede abonar a la reflexión on- 
tológica de la formación del símbolo en el niño. Los estudios que se han desarrollado principalmente se enfocan en el símbolo de la sustancia, por lo que tal vez sería interesante estudiar cómo funciona y se forman las representaciones de la experiencia, lo dinámico, los procesos.

Con carácter multidisciplinario, desde la filosofía, la lingüística, la historia y con énfasis en una mirada psicolingüística, exponemos la evolución sociohistórica semiótica del verbo en la lengua española.

Debates en torno a la definición, significado, funcionamiento de la representación del verbo (oral y escrito) en el idioma español

Considerando que el concepto de verbo no es un "universal lingüístico" y que advertimos características distintas entre los idiomas, acotamos la revisión a la lengua española. La definición de verbo ha generado grandes debates a través de la historia. Desde los gramáticos grecolatinos en la época clásica hasta nuestros días no hay un acuerdo del criterio a considerar para su definición. Se ha definido con base en distintos criterios dando como resultado una gran gama de intentos por delimitarlo. Por lo tanto, en este apartado trataremos de esbozar cómo se han construido distintas definiciones de verbo, desde una perspectiva histórica, a través de algunos representantes de la lengua, esto para comprender la complejidad del concepto y de su representación.

La revisión histórica que esbozamos a continuación se basa en los trabajos de González (1978 y 2011), de los que extrajimos ideas, épocas, representantes y definiciones que nos sirvieron para advertir la evolución y criterios preponderantes utilizados para caracterizar la palabra verbo.

\section{La noción de verbo en la Antigüedad}

Desde los primeros intentos para definir al verbo se han considerado criterios semánticos, morfológicos y sintácticos. Según González (1978), el debate de la definición de verbo comenzó en la Antigüedad con Platón, quien distinguió dos partículas que opuso entre sí: "onoma" y "rema". El término rema se empleó para aludir al sentido de predicado y cuyo elemento central era el verbo. 
Aristóteles coincidió con Platón en que el verbo es un elemento central de la predicación y agregó que guarda relación con la temporalidad de la significación en la emisión. Posteriormente, González (1978) informó que Robins asegura que "los representantes del estoicismo (cuyo movimiento filosófico en el periodo helenístico tuvo gran difusión en el mundo grecorromano) regresaron a la perspectiva del verbo como predicado de Platón. Además de coincidir con Aristóteles en la dimensión de temporalidad, identificaron el aspecto acabado o inconcluso" (p. 67).

Con respecto a Dionisio de Tracia (170-90 a.C.), González (1978) afirma que a éste gramático griego que perteneció a la escuela alejandrina, le debemos la definición que se hizo clásica del verbo: "parte de la oración sin inflexiones de caso, que admite las de tiempo, persona y número y que expresa una actividad o un estado afectivo" (p. 67).

González (1978) encontró que Panini (siglo IV a.C.), gramático de la India antigua, propuso una "definición coincidente con la de Dionisio de Tracia en cuanto a la flexión verbal (tiempo, persona y número) y agregó la consideración de que el verbo es el núcleo del predicado" (p. 67). Tanto Dionisio de Tarcia como Panini, coincidieron en incluir los criterios morfológico, sintáctico y semántico para delimitar al verbo. Además, Panini estableció la relación funcional sintáctico-semántica del verbo como parte de una unidad mayor: el enunciado.

En esta misma época, los latinos Varrón (116-27 a.C.), Donato (siglo IV d.C) y Prisciano (siglos V-VI d.C.) consideraron otros elementos para la definición de verbo. Varrón, quien fue nombrado por Julio César como el director de la primera biblioteca pública de Roma, distinguió entre nombre y verbo considerando los accidentes gramaticales. El nombre o sustantivo cuenta con caso pero no con tiempo, al contrario del verbo, que presenta tiempo pero no caso. Por su parte, Donato, gramático latino reconocido, consideró además del criterio morfológico, el semántico para describir al verbo. En González (1978) encontramos la definición de verbo de Donato: "pars orations, cum tempore et persona, sine casu, aut agere aliquid aut pati aut neutrum significans" (p. 70) (parte de la oración, con tiempo y persona, sin caso, que se refiere a hacer cualquier cosa o que se actúa 
sobre ellos o ningún hacer pero que indica estado). Por último, cabe mencionar que Prisciano elaboró una descripción exclusivamente morfológica del verbo latino.

Los primeros intentos por definir al verbo tomaron en cuenta, en primera instancia, la oposición con la sustancia, es decir, entre lo dinámico y lo estático, por lo que el criterio semántico prevaleció en su delimitación. Este rasgo semántico era general y no consideraba la relación con lo formal. Asimismo, los gramáticos grecolatinos consideraron en estas primeras distinciones estos aspectos morfológicos: temporales, aspectuales, y también el comportamiento sintáctico del verbo como parte de una unidad mayor. A continuación, presentamos las aportaciones de los gramáticos medievales.

\section{La noción de verbo en el siglo XII}

En el siglo XII los gramáticos escolásticos enfatizaron el criterio exclusivamente semántico de los verbos, ligado al carácter racional del discurso, como lo muestra Breva (2005) en la siguiente cita:

Escaligero intenta explicar la causación del lenguaje a partir de la naturaleza. Por eso, en el uso busca lo que las palabras, o sea sus marcas formales en cuanto poseedoras de significado, representan con relación al ser. Así, admite en el nombre seis accidentes (como reflejo de las categorías relativas de la naturaleza, que dependen de una categoría absoluta) y da cuenta del proceso de causación de los accidentes a partir de la realidad. Estudia las causas de los nombres y de los verbos (ambos como categorías absolutas de la realidad) y, en mucho menor grado, de las construcciones sintácticas. En su modelo, encajan perfectamente la distinción que efectúa entre caso y declinación; el primero lo utiliza para referirse a la captación y comprensión del fenómeno natural por el entendimiento, mientras que la declinación es la marca o signo de dicha operación mental representada en el lenguaje. (p. 309) 
Adicionalmente, González (1978) señaló los criterios de Tomás de Erfurt para quien "el modo esencial de significar del verbo indica la cosa por su ser y distancia de la sustancia (verbum est parsorationis significans per modum ese distantis a substantia); el modo de significar por el ser se origina de lo que fluye y de la sucesión; y el modo por la distancia se origina de una propiedad de la esencia determinada" (García, 1960: 113 en González, 1978). Es decir, el concepto de verbo se define en contraste o en relación con la sustancia o al nombre bajo el criterio semántico.

\section{La noción del verbo en el siglo XV}

El nacimiento de la gramática de la lengua española se asocia con la conceptualización más compleja del verbo considerando varios criterios interrelacionados. Las primeras gramáticas del español se publicaron en el siglo $\mathrm{XV}$, por lo que se conoce a esta época como el nacimiento de la lingüística española. Comienza con la publicación de la Gramática castellana de Nebrija (1492) y concluye con el Arte de la lengua castellana de Gonzalo Correas (1626). La Gramática... de Nebrija incluye en su libro tercero (La etimología y dicción) varios capítulos relacionados con la definición del verbo: en el primer capítulo, sobre las diez partes de la oración de la lengua castellana, incluye como una de ellas al verbo; el capítulo décimo lo dedica exclusivamente al verbo y continúa con la descripción en el capítulo undécimo "De los circunloquios del verbo", en los capítulos duodécimo, decimotercero y decimocuarto expone respectivamente temas "del gerundio del castellano", "del participio", "del nombre participial infinito"1. Nebrija ya señalaba el comportamiento atípico de las formas no personales del verbo y le dedicó un capítulo exclusivo a cada una. Las formas no personales han sido parte del debate de los gramáticos sobre la pertinencia de considerarlas dentro de la categoría verbal ya que pueden funcionar como sustantivos, adjetivos o adverbios.

En su Gramática..., Nebrija resalta la cualidad predicativa del verbo y le otorga centralidad ya que por sí solo puede construir una oración.

1. Consultado en http://www.antoniodenebrija.org/libro3.html\#10 en marzo de 2014 
Verbo es una de las diez partes de la oración: el cual se declina por modos y tiempos sin casos. E llámese verbo que en castellano quiere decir palabra: no porque las otras partes de la oración no sean palabras: mas porque las otras sin ésta no hacen sentencia alguna: ésta por excelencia llamóse palabra.

El verbo, pues, es el núcleo del predicado y puede formar una oración por sí solo.

La Gramática Castellana de Villalón fue publicada en Amberes en 1558. En ella se señaló que el rasgo semántico de los verbos está atado a los accidentes gramaticales. González (1978) reportó que Villalón, siguiendo a Donato, define al verbo de la siguiente manera:

Verbo es una boz que significa hazer, padecer (que llama el Latino action o passion) alguna obra en alguna diferencia de tiempo [...] que hay solas tres diferencias de tiempo por donde se varía el verbo por la lengua castellana [...] segundo es de notar que se varía el verbo comúnmente por cada cual de estas tres diferencias de tiempo por tres personas [...] tercero es de notar que juntamente se varía el verbo por dos números. (p. 69)

La definición que aporta Gonzalo Correas, gramático representante del nacimiento de la lingüística española, sigue la línea de Dionisio de Tracia y los gramáticos latinos. Según Hernando (2011), de quien recibe la mayor influencia es de Nebrija pero, a diferencia de él, trata el fenómeno verbal con mayor detalle y presta atención a aspectos de la lengua o vocabulario histórico. En la definición que presenta González (1978) de Correas sobresale también el criterio semántico ligado al morfológico. La definición que propone Correas a mediados del siglo pasado, la presenta González (1978): "verbo es aquella palabra que significa el hazer i obrar, i dezir las cosas i ser hechas, i obradas, i decirse: i tiene boz y coxugación. La conxugazión se reparte en tiempos, los tiempos en personas, i números, i modos" (p. 70).

La gramática española de Lovaina (1555) definió al verbo recurriendo nuevamente a la diferencia platónica de lo dinámi- 
co frente a lo estático. Bartolomé Jiménez Patón (1569-1640), gramático español, afirmó que "el verbo será aquella parte de la oración cuya naturaleza dura en quanto se exercita la tal cosa, como corre, ama" (González, 1978: 70). Nuevamente recurre sólo al criterio morfológico.

Los gramáticos renacentistas que aquí presentamos compartían el interés de conseguir para la lengua castellana un lugar a la altura del latín, del griego o del hebreo, por lo que se preocuparon por describir exhaustivamente los elementos y las reglas que la rigen. En el caso del verbo, las descripciones partieron de la oposición estática-dinámica de la Antigüedad para considerar todos los aspectos que contiene el verbo. También, se les atribuyó a los gramáticos de esta época la reducción de los tiempos verbales en tres.

\section{La noción de verbo en el siglo XVII}

Para González (1978), "las gramáticas racionalistas en el siglo XVII se caracterizaron por su orientación filosófica, sobre todo de las escuelas francesas de Port-Royal. Los gramáticos racionalistas tuvieron una gran influencia de los trabajo de Descartes para realizar estudios comparativos entre lenguas con el fin de distinguir la unidad de la gramática profunda" (p. 70). Los gramáticos racionalistas propusieron una clasificación de las palabras alterna a las clases gramaticales clásicas. El criterio semántico fue el que utilizaron para la reagrupación. En este sentido, opusieron las palabras que significan objetos del pensamiento y las palabras que significan maneras del pensamiento, por ejemplo, los sustantivos y pronombres como representantes de los objetos del pensamiento y el verbo como una de las clases de palabras que significan maneras del pensamiento. De acuerdo con lo anterior, González (1978) encontró que definen el verbo como una palabra cuyo principal uso es significar una afirmación "vox significans affirmationan" (p. 70).

El criterio semántico-lógico racionalista, por sí solo, no caracteriza suficientemente al verbo. La clasificación propuesta por los gramáticos racionalistas aportó la posibilidad de diferenciar la actividad cognitiva necesaria para concebir las cosas, 
distinta del juicio sobre las cosas. La clasificación contribuyó a las reflexiones sobre la actividad cognitiva diferenciada para significar las clases de palabras pero debido a que no está ligada al carácter formal ni sintáctico ni funcional carece de suficiencia.

\section{La noción de verbo en el siglo XVIII}

La gramática académica del siglo XVIII, como lo reportó González (1978), la primera edición de la Gramática de la lengua castellana (1771) define al verbo como "la parte principal de la oración que sirve para significar la esencia, la existencia, la acción, pasión y afirmación de todas las cosas animadas e inanimadas, y el exercicio de qualquiera facultad que tienen estos casos, o se les atribuye" (p. 70). Es decir, caracterizaron al verbo desde las perspectivas sintáctica y semántica. Resulta interesante que integraron clases semánticas y consideraron cualidades de la sustancia.

\section{La noción de verbo en los siglos XIX y XX}

La gramática funcional del siglo XIX otorgó especial atención al comportamiento sintáctico del verbo y aportó diferentes puntos de vista sobre el criterio semántico. Andrés Bello, considerado el más importante gramático y lingüista hispano de este siglo, resaltó la importancia del verbo al considerarlo como la palabra esencial y primaria de sujeto, esto según la Academia Española en 1973 encontrado por González (1978). Además, de acuerdo con González (2011 y 2012), Bello fue el primero en observar la importancia del comportamiento sintáctico del verbo al reconocerlo como un atributo de la preposición. Además, consideró la relevancia para la lengua de la dinámica de los sintagmas en general y del sintagma verbal en particular. También rechazó el criterio semántico-lógico pues no consideró la forma ni el funcionamiento sintáctico. En la misma línea, Rodolfo Lenz, gramático hispanoamericano, coincidió con Bello en el criterio funcional del verbo y en no incluir la perspectiva semántica al definirlo como fenómeno del sujeto: "es una palabra que añadida a un sujeto, expresa con él un juicio completo e independiente y forma una oración" (González, 1978: 71). 
Alonso y Henríquez Ureña aportaron un nuevo punto de vista semántico-lógico al concepto de verbo al definirlo como "formas especiales del lenguaje con las que pensamos la realidad como un comportamiento del sujeto" (idem: p. 71). Es decir, lo caracterizaron bajo la consideración de una actividad cognitiva o forma de pensar la realidad, como un comportamiento que puede ser acción, estado, etcétera. En este sentido, la definición no incluyó a los verbos copulativos, auxiliares ni no finitos o no personales.

Antoine Meillet (1866-1936), reconocido como uno de los mayores representantes de la lingüística francesa de principio del siglo XX, modificó el punto de vista semántico-funcional al oponer el nombre y el verbo como una característica esencial de las lenguas indoeuropeas. Reportado por González (1978), Meillet en 1948 afirmó que el "nombre, indica las cosas, ya se trate de objetos concretos o de nociones abstractas, de seres reales o de especies. Y el verbo, indica los procesos, ya se trate de acciones, de estados o de paso de un estado a otro" (p. 72). Nuevamente, excluyó a los verbos copulativos que carecen de significado pleno. Varios autores (Muñoz Cortés, 1958; Criado de Val, 1958; Galichet, 1949; Sechehaye, 1950) coinciden con la caracterización del verbo como proceso apoyando una caracterización semántica funcional.

Por su parte, Bernard Pottier y Émile Benveniste, dos lingüistas europeos reconocidos del siglo pasado, coincidieron en destacar la importancia del verbo al señalar que es la única clase de palabra que puede realizar un enunciado coherente. Martin (1971) se refiere a que la "teoría nodal del verbo" expuesta por estos dos autores reconoce al "verbo como el signo básico de la oración realizada" (pp. 34-35).

\section{La noción contemporánea de verbo}

Los gramáticos y lingüistas contemporáneos coinciden en definir al verbo como el núcleo del sintagma verbal (SV) y observan también los rasgos formales (morfológicos). Así, el hispanista Gómez Torrego (2007), en La Gramática didáctica del español, define al verbo de la siguiente manera: 
El verbo es una clase de palabra -o categoría léxica- que desde el punto de vista formal se compone de raíz y desinencias, y desde el punto de vista funcional es siempre el núcleo sintáctico del predicado de la oración. En relación con la naturaleza gramatical, el verbo puede llevar o no complementos. (p. 137)

Por su parte, Marín (2002), en la Gramática española, coincide con Alarcos y otros lingüistas, en la siguiente definición: "Entendemos por verbo aquella clase de palabra susceptible de tener flexión de tiempo, modo, aspecto, número y persona, y que desempeña la función de núcleo del sintagma verbal". También afirman que "es el verbo el que selecciona el sujeto, y que el sujeto es uno de los actantes del verbo" (p. 196).

Según González (2011-2012), en la Gramática descriptiva de la lengua española, dirigida por Bosque y Demonte (1999), y la Nueva gramática de la lengua española -de RAE y AALE, 2009-, "se describe con profusión la morfología y el comportamiento sintáctico del verbo -con el inevitable uso de criterios semánticossin que aparezca en ninguna parte la definición o caracterización de esa clase sintáctica de palabra, categoría gramatical o simplemente clase de palabra" (pp. 185-186), dato que corroboramos en la revisión que realizamos de estas gramáticas.

Como se puede observar en las definiciones contemporáneas del verbo, la Nueva gramática de la lengua española (2010), Gómez Torrego (2007), Marín (2002), Bosque y Delmonte (1999) coinciden en considerar los criterios formales (morfológicos) y funcionales (comportamiento sintáctico con relación al semántico) del mismo.

\section{Consideraciones finales}

Desde la perspectiva de la semiótica y la psicología evolutiva la revisión sociohistórica de la construcción del significado del verbo como representante de lo dinámico puede contribuir a descubrir mecanismos comunes que eventualmente se pueden traducir en pistas para comprender el desarrollo cognitivo de la formación y desarrollo del símbolo de la experiencia. Es decir, 
los mecanismos comunes (no los resultados del conocimiento) podrían colaborar para establecer comparaciones en cómo se origina en la psicogénesis de los niños los conceptos asociados a lo dinámico y cómo han evolucionado en la ciencia (la lingüística perteneciente a las ciencias culturales y sociales).

La revisión sociohistórica no evidenció que la significación de lo dinámico se basara en conceptos a priori o innatos ni tampoco como datos de los sentidos o empíricos, toda vez que se muestra la evolución de la significación de un signo que pertenece a un sistema de representación del mundo a través del lenguaje. Los mecanismos comunes utilizados para significar al verbo parten de la base de la oposición con la sustancia, es decir, lo estático frente a lo dinámico. Este mecanismo se mantuvo a lo largo de las concepciones desarrolladas por los gramáticos y lingüistas. Es un criterio semántico que no evidencia la relación con lo formal. Este mecanismo común tuvo reformulaciones en las que, incluso, recategorizaron gramaticalmente los objetos del pensamiento (sustantivos y pronombres) y los modos del pensamiento (verbo) para caracterizar la oposición. No se sostuvo esta categorización pero sí abonó a diferenciar la actividad cognitiva para concebir lo que resulta diferente a elaborar el juicio desde una perspectiva semántico-lógica con base en el carácter racional del discurso.

Para completar este mecanismo se observó que coordinaron otros criterios más o menos relacionados con los niveles de caracterización para significar al verbo. Algunos gramáticos enfatizaron los aspectos morfológicos temporales y aspectuales al principio y en la evolución más tardía se incluyeron esquemas más desarrollados en los que se distingue la complejidad de significados tanto plenos como funcionales. Para entender este mecanismo común, el ejemplo desarrollado desde la morfotáctica puede ayudar: 


\section{(Raíz + Vocal temática) +sufijo + sufijo 1(TAM) 2 (NP)}

Ejemplo

$\begin{array}{lll}\mathrm{Am}+\mathrm{a} & +\mathrm{ba}+\mathrm{mos} & \text { (pretérito imperfecto) } \\ \mathrm{Am}+\mathrm{a} & +\mathrm{rá}+\mathrm{n} & \text { (futuro) }\end{array}$

Figura 1. Esquema morfotáctico verbal. RAIZ = base léxica, vocal temática $=\mathrm{a}, \mathrm{e}, \mathrm{i}$, sufijo $1=$ informa sobre el tiempo, aspecto y modo, sufijo 2 = es el sufijo de concordancia y se refiere al número y a la persona.

También, como parte de los mecanismos comunes hubo gramáticos que acentuaron al verbo como parte de la oración considerando las categorías gramaticales como distintas clases de palabras. Este rasgo para significar al verbo se extiende a las relaciones sintácticas que se establecen en la oración que en la lengua española cuenta con gran flexibilidad con el orden de los constituyentes. Y encuentran también comportamientos atípicos en las formas no personales del verbo (gerundio, participio e infinitivo) ya que funcionan como adverbios, adjetivos o sustantivos. Este mecanismo evolucionó hasta coordinar los aspectos formales del verbo en el contexto del sintagma verbal y la actividad cognitiva o forma de pensar la realidad expresado desde la función y la significación incluyendo la forma y sus variaciones. La concepción contemporánea de la representación de lo dinámico incluye lo formal conformado por la raíz y las desinencias susceptibles a tener flexión y lo funcional que considera al verbo como el núcleo sintáctico del predicado que desempeña la función de núcleo del sintagma verbal y además selecciona al sujeto (el sujeto es uno de los actantes del verbo); es decir, coordina los criterios formal, gramatical y sintáctico-semántico. Significar la experiencia coordinando los criterios anteriores permite construir significados complejos y ricos que representan lo dinámico de manera más completa.

Un ejemplo para entender los alcances para la significación del verbo desde esta perspectiva amplia es que los verbos representan procesos que a su vez se pueden clasificar 
en clases semánticas con el fin de significarlos. Las clases semánticas son dominios conceptuales que, al mismo tiempo, se convierten en acepciones del mismo verbo. En el estudio Los verbos más frecuentes en textos escritos para niños (Forzán, 2014) se encontró que el verbo "llevar" con una frecuencia alta presentó el mayor número de entradas léxicas registrando 9 clases semánticas. Para comprender lo que se refiere en estas dos entradas léxicas de dos textos se distinguen las distintas acepciones: "Camile llevó su relato a la escuela" (Camile y los girasoles) a diferencia de "El problema es que Rafles se lleva muy mal con su mamá" (Mamá tiene súper poderes). Ese dato da cuenta de la gama amplia de posibilidades de significar un verbo si se entiende desde la perspectiva coordinada.

Los mecanismos comunes ya descritos pueden colaborar eventualmente para compararlos con la actividad cognitiva de significar a través de la lengua (como manifestación concreta del lenguaje y de procesos cognitivos asociados) en general, y de significar la representación de la experiencia en particular en un continuo que se origina desde antes del nacimiento en la biología y prosigue en el desarrollo de actividades que después se convierten en cognitivas y están en permanente continuidad funcional de los mecanismos en todo el proceso hasta llegar a las significaciones más acabadas desarrolladas por los científicos (lingüistas y estudiosos de la lengua). Es decir, el proceso constructivo.

Desde las dos perspectivas del desarrollo cognitivo, individual (Piaget) y social (Vygotski), serían válidas e interesantes las siguientes preguntas: ¿cómo se generan en la psicogénesis o cómo se da el proceso de interiorización del concepto de la experiencia y cómo se desarrolló o evolucionó en la ciencia?

Si se renuncia al apriorismo y al empirismo, el conocimiento es una construcción que se desarrolla a través de la interacción. Y la conceptualización se construye al organizar las interacciones con el mundo exterior. Las interacciones desde el desarrollo cognitivo individual y social tienen lógicas diferentes pero, en cualquier caso, indagar sobre los procesos de significación del símbolo de la experiencia puede ser eventualmente interesante. 
Desde la perspectiva del desarrollo cognitivo individual la interacción se da entre el sujeto y el objeto. En este caso, el objeto es una construcción cultural convenido socialmente y constituido por signos arbitrarios que en la primera infancia necesariamente se dará por medio del uso del adulto con quien interactúa el bebé. Por su parte, en el modelo explicativo del desarrollo cognitivo social la interacción es triádica en la que participa el sujeto, el objeto cultural y el adulto.

El desarrollo individual sostiene que es el sujeto quien reconstruye el sistema de representación a través de la interacción planteando hipótesis que dan como resultado concepciones y/o conceptos en acto que dan cuenta de la coordinación o no de los constituyentes para significar la representación de lo dinámico. En este sentido, podría resultar relevante estudiar la clase de signos que entienden y usan los niños para comunicar los procesos en contraste con lo estático antes de la etapa lingüística, y posteriormente, los errores, procedimientos y formulaciones que ponen en marcha como manifestación concreta de las concepciones de la representación de la experiencia. Es decir, entender a los niños como lingüistas o científicos.

En el desarrollo social se afirma que el sistema de representación (objeto) es enseñado por el adulto y es el sujeto en un proceso intrasubjetivo quien realiza la interiorización. En este sentido, se anticipa que puede ser interesante indagar desde la perspectiva pragmática los andamiajes que los adultos ofrecen a los bebés/niños para que puedan significar e interiorizar la representación de lo dinámico en contraste con lo estático. Nos referimos al estudio de signos y códigos mediados por los adultos en la interacción triádica que eventualmente abonan al proceso de significación del bebé o niño.

\section{Referencias}

Bosque, I. (2010). Nueva gramática de la lengua española. Manual. Madid: RAE-Espasa Calpe.

Bosque, I. y Delmonte, I. (eds.) (1999). Gramática descriptiva de la lengua española, España: Espasa Calpe.

El'konin, D. (1966). Symbolics and its funciones in the play of chil- 
dren. Soviet Education, 8(3), 35-41.

Forzán, A.L. (2014). Los verbos más frecuentes en textos escritos para niños (Tesis de maestría). Universidad Autónoma de Querétaro, Santiago de Querétaro, Qro.

González Calvo, J. M. (1978). El concepto dew verbo. Anuario de estudios filológicos, (1), 65-90.

(núm. 34-35, 2011 y 2012). Caracterización del verbo como clase de palabra en español. Revista de filología y su didáctica, 181-193.

Halliday, M. A. K. (1985). An Introduction to Functional Grammar. London: Edward Arnold.

Halliday, M. A. K. y Matthiesen, C. M. (2004). An Introduction to Functional Gramar. London-New York: Hodder Arnold.

Halliday, M. y Matthiessen, M. (2006). Contruing Experience throug Meaning: A Language-based Approach to Cognition. London-New York: Continuum.

Inhelder, B., Lézine, L., Sinclair, H., y Stambak, M. (1972). Les débuts de la fonction symbolique. Archives de Psychologie, 41, 187-243.

Marin, F. M. (2002). Gramática española. Madrid: Editorial Síntesis. McCune-Nicholich. L. (1981). Toward symbolic functioning: structure of early pretend games and potential parallels with language. Child Development, 52(3), pp. 785-797.

Muñoz, C. M. (1958). El español vulgar: descripción de sus fenómenos y métodos de corrección (Vol. 2). Sección de Publicaciones de la Secretaría General Técnica, Ministerio de Educación Nacional.

Nebrija, A. D. (1999). Gramática de la lengua castellana. Recuperado de http://www.antonionebrija.org/libro3.html\#10

Palacios, P. (2009). Origen de los usos simbólicos de los objetos en los niños en contextos de comunicación e interacción triádicos (Tesis doctoral). Universidad Autónoma de Madrid, España.

Piaget, J. (1959 y 2012). La formación del símbolo en el niño. México: FCE. Piaget, J., García, R., García, R. V., y Lara, J. (1989). Psychogenesis and the History of Science. Columbia University Press.

Rodríguez, C. y Moro, C. (2002). Objeto, comunicación y símbolos. Una mirada a los primeros usos simbólicos de los objetos. Estudios de Psicología, 23(3), 323-338. 
Tomasello, M. (1999). El origen cultural de la cognición. Cambridge: Harvard University Press.

Torrego, L. G. (2007). La gramática didáctica del español. España: SM. Vigotsky, L. (1930 y 1996). El desarrollo de los procesos psicológicos superiores, Barcelona: Crítica. 